\title{
MetA-ANALYSIS: COVID-19 DiseAse SEVERITy CORRELATES WITH SMOKING STATUS
}

\author{
Corresponding author: \\ (D) Édouard Lansiaux \\ Henry Warembourg School of Medicine, Medical Student \\ Lille University, 59000, Lille, France \\ edouard.lansiaux.etu@univ-lille.fr \\ Philippe P. PébaÿPh.D. \\ NexGen Analytics \\ Sheridan, WY 82801, U.S.A. \\ philippe.pebay@ng-analytics.com \\ Dean-Laurent Picard, M.Sc \\ Conservatoire National des Arts et Métiers \\ 75141 Paris, France \\ il@pi.cards \\ D Joachim Son-Forget, M.D.-Ph.D. \\ Assemblée Nationale \\ 75355, Paris, France \\ joachim.son-forget@assemblee-nationale.fr
}

Keywords: COVID-19; Coronavirus; Respiratory Distress; Tobacco; Smoking;

Correlation; Statistics; Conditional; Probability; Regression; China; U.S.A.

All authors have completed and submitted the International Committee of Medical Journal Editors form for disclosure of potential conflicts of interest. No potential conflicts of interest were disclosed. 
The novel COVID-19 disease is a contagious acute respiratory infectious disease whose causative agent has been demonstrated to be a new virus of the coronavirus family, SARS-CoV-2. Multiple studies have already reported that risk factors for severe disease include older age and the presence of at least one of several underlying health conditions. However, a recent physiopathological report and the French COVID-19 scientific council have postulated a protective effect of tobacco smoking.

Thanks to a meta-analysis, we have been able to demonstrate the statistical significance in this regard of twelve series from China, France and in the US, reporting three different smoking status (current smoker,former smoker, with a smoking history) as well as disease severity (with respectively odds-ratio of 1.78 [1.08-3.10], 4.60 [3.13-7.17], 2.74 [0.63-5.89]). Subsequently and using a Bayesian approach we have established that past, and present smoking is associated with more severe COVID-19 outcomes. Finally, we refute claims linking general population smoking status $\left(\mathrm{N}=\mathrm{O}\left(10^{8}\right)\right.$ or $\left.\mathrm{O}\left(10^{9}\right)\right)$ to much smaller disease course series $\left(\mathrm{N}=\mathrm{O}\left(10^{4}\right)\right)$. The latter point in particular is presented to stimulate academic discussion, and must be further investigated by well-designed studies.

\section{IMPLICATIONS}

Recent preliminary estimates of the prevalence of selected underlying health conditions among patients with COVID-19, in China, France and in the United States, show that individuals with underlying health conditions appear to be at higher risk for more severe COVID-19.Thanks to a meta-analysis, we have concluded that the only significant findings that can be confidently asserted from the series discussed in this article, is that past, and present smoking is associated with more severe COVID-19 outcomes. 
The novel coronavirus pneumonia (COVID-19) is a contagious acute respiratory infectious disease whose causative agent has been demonstrated to be a new virus of the coronavirus family, SARS-CoV-2. This illness was first evinced in December 2019 in the Seafood Market of Wuhan, Hubei Province, in southern China ${ }^{1,2}$. Patients with the coronavirus pneumonia have a fever, and the temperature above 38 degrees Celsius with symptoms such as dry cough, fatigue, dyspnea, difficulty breathing, and diarrhea ${ }^{1-5}$. There is a high transmission for this disease, which, as result of this and other factors such as international travel and trade, has now turned into a pandemic, with hundred thousands of individuals confirmed to be infected worldwide - and most likely millions of unreported cases $^{5}$.

Recent preliminary estimates of the prevalence of selected underlying health conditions among patients with COVID-19, in China as well as in the United States, show that individuals with underlying health conditions appear to be at higher risk for more severe COVID-193,6. A recent Greek epidemiological review suggests that smoking is most likely associated with the negative progression and adverse outcomes of COVID-197. Meanwhile, a recent physio-pathology study has formulated the hypothesis that the effectiveness of ACE inhibitors/angiotensin II receptor blockers and nicotine in patients infected with COVID-198.

The smoking prevalence in China, in France and in the U.S. have been previously and broadly documented: these are, respectively, of $26.6 \%, 30 \%$ and $19.7 \% 9,10,11$. Furthermore, the president of the COVID-19 Scientific Council of France recently postulated that nicotine may have a protective role against COVID-19 infection ${ }^{12}$. Thanks to a meta-analysis based upon twelve studies $3,6,13-22$, we can observe that the prevalence of past/current smokers is higher in COVID-19 severe infected patients. In this context, we would like to know whether the past/current smoking status entails higher probability of a severe course of COVID-19 illness, as compared to having never smoked.

\section{METHODS}

\section{Study and Participants}

We conducted a systematic search using ReseachGate on May 15, 2020, with the search term: ((smoking) OR (characteristics) OR (risk factors) OR (outcomes) OR (smoker $\left.{ }^{*}\right)$ ) AND ((COVID-19) OR (COVID) OR (coronavirus) OR (sars cov-2) OR (sars cov 2) OR (severity)) for studies published between January 1, 2020 and May 15, 2020. One author extracted information for each study, screened the abstract or the full text, with questions resolved through discussion among both authors. There were no language restrictions. The source and targeted populations are the whole humanity in view of the ongoing COVID-19 pandemic. The eligible population is constituted by all Chinese, French and American already included in previous papers.

The study was conducted by a consortium of two data analysts, a MD-PhD specialized in radiology, and a medical student in clinical years. NexGen Analytics had no role in designing the study, nor in making the decision to submit manuscript to the publication, nor did it receive any fee or compensation in the context of this work. The first author vouches for the data and analyses, as well as for the fidelity of this report to the study protocol. 
The studied and included population gathers patients from all studies upon COVID-19 with informations concerning the smoking status. The inclusion criteria were observationnal studies with as outcomes smoking status and the COVID-19 infection severity. The exclusion criteria were: incomplete data upon COVID-19 infection severity or smoking status, meta-analysis.

\section{Outcome Measures}

Our null hypothesis $\left(\mathrm{H}_{0}\right)$ was the orthogonality between two variables: the smoking status $(\mathrm{X})$ and the COVID-19 Symptoms Severity $(\mathrm{Y})$. Each variable can take different values: for the smoking status $(X)$, it was a never smoker $\left(X_{1}\right)$ or a current smoker $\left(X_{2}\right)$ or a former smoker $\left(\mathrm{X}_{3}\right)$ or a patient with a smoking history $\left(\mathrm{X}_{4}\right)$; for the COVID-19 Symptoms Severity $(\mathrm{Y})$, it was a mild (non-hospitalised) $\left(\mathrm{Y}_{1}\right)$ or a severe (hospitalised, ICU or not) $\left(\mathrm{Y}_{2}\right)$ symptoms severity.

\section{Statistical Analysis}

Each sample was analysed separately. First, we had to calculate for each sample (if they haven't been calculated by the authors) : the odds ratio with the never smoker as reference for current smokers, former smokers and patients with a smoking history. We then calculated, for each observed sample, the expected odd ratios assuming $\mathrm{H}_{0}$ expected sample: in each case, we multiplied the two corresponding sums and subsequently divided by the actual total. In this way, we were able to apply a $x^{2}$ test to compare the observed table to the expected table, for each sample. The $p$-value was subsequently computed in order to evince a statistically significant difference between the observed and the expected tables.

\section{RESULTS}

\section{Populations}

We found 79 studies on ResearchGate. Thirty-seven studies met the inclusion and exclusion criteria. A total of 29 observational studies and eight meta-analyses were identified. All observational studies reported the prevalence of smoking amongst hospitalized COVID-19 patients. Twelve of the 29 observational studies containing data on smoking status by severity of COVID-19 outcomes. After a short treatment of the initial data from both series (Table 1), in particular to eliminate incomplete data and studies outside our inclusion criteria, we have obtained the observed data for each study (Table 2).

\section{Outcomes}

We estimated the expected data on each case by multiplying the two corresponding sums and then by dividing by the total effective, for each sample. In these conditions, thanks to the $x^{2}$ test, we were able to estimate, for both samples, trust interval and the $p$-values where the difference between observed and expected data are significant (Table 3). Indeed, the association between COVID-19 severity infection and the 
of 1.78 [1.08-3.10] and 4.60 [3.13-7.17], with a $p$-value of $1.22^{*} 10^{-1}$ and $1.87^{*} 10^{-2}$. The smoking history is linked to the COVID-19 severity infection by an odds ratio of 2.74 [0.63-5.89] with a p-value of $6.11^{*} 10^{-2}$ (Table 4). Subsequently and using a Bayesian approach we have established that past and present smoking is associated with more severe COVID-19 outcomes.

\section{DISCUSSION}

Subsequently, by computing the empirical probability distributions conditioned on smoking status, we have established that past and present smoking is associated with more severe COVID-19 outcomes, in those samples. Nevertheless, our study has some limitations:

1. The difference between smoking status as observed across populations, and the same observed in our small clinical datasets (Table 2) is significant. As a result, the previously claimed relationship between former/current smoking status and a COVID-19 disease severity may not be confidently estimated from a global population.

2. Only adults were considered to compute smoking prevalence ${ }^{10}$.

However, regarding the first limitation above, we contend that claims linking general population smoking status, computed across populations with cardinalities $\mathrm{N}$ in the order of $\mathrm{O}\left(10^{8}\right)$ or even $\mathrm{O}\left(10^{9}\right)$ with broadly varying smoking habits (e.g. already rural vs urban divide in this regard), to much smaller disease course series $\left(\mathrm{N}=\mathrm{O}\left(10^{4}\right)\right)$, are at best imprudent and at worst marred by selection bias, especially as the latter regard a fraction of patients from the same urban area. We therefore claim that specific smoking status data, relevant to the concerned geographic areas, is required to evince a statistically significant under-representation of smokers among COVID-19 patients. An alternative argument could be made from a physio-pathological standpoint as well: indeed, previous studies and assertions describe a hypothetical protector role of nicotine against COVID-19 infection ${ }^{8}$, but these are largely speculative at this point and require laboratory confirmation. We therefore conclude that the only significant findings that can be confidently asserted from the series discussed in this article, is that past and present smoking is associated with more severe COVID-19 outcomes.

\section{ACKNOWLEDGEMENTS}

The authors declare no conflicts of interest.

\section{REFERENCES}

1. Wang D, Hu B, Hu C, et al. Clinical Characteristics of 138 Hospitalized Patients With 2019 Novel Coronavirus-Infected Pneumonia in Wuhan, China. JAMA. 2020;323(11):1061-9.

2. Huang C, Wang Y, Li X, et al. Clinical features of patients infected with 2019 novel coronavirus in Wuhan, China. The Lancet. 2020 Jan 24;395. 
China. New England Journal of Medicine. 2020 Feb 28;

4. Chang D, Lin M, Wei L, et al. Epidemiologic and Clinical Characteristics of Novel Coronavirus Infections Involving 13 Patients Outside Wuhan, China. JAMA. 2020 Feb 7;323.

5. Diao K, Han P, Pang T, Li Y, Yang Z. HRCT Imaging Features in Representative Imported Cases of 2019 Novel Coronavirus Pneumonia. Precision Clinical Medicine. 2020 Feb 11;

6. Chow N, Fleming-Dutra K, Gierke R, et al. Preliminary Estimates of the Prevalence of Selected Underlying Health Conditions Among Patients with Coronavirus Disease 2019 - United States, February 12-March 28, 2020. Morbidity and Mortality Weekly Report. 2020 Apr 3;69(13).

7. Vardavas C, Nikitara K. COVID-19 and smoking: A systematic review of the evidence. Tobacco Induced Diseases. 2020 Mar 20;18.

8. Patel A, Verma A. COVID-19 and Angiotensin-Converting Enzyme Inhibitors and Angiotensin Receptor Blockers: What Is the Evidence? JAMA. 2020 Mar 24;

9. World Health Organization, US Center for Disease Control and Prevention, RTI International. Western Pacific Region - China - National Population Survey - Global Adult Tobacco Survey (GATS) Topic: Tobacco Use [Internet]. Global Tobacco Surveillance System Data (GTSSData). Available from:https://nccd.cdc.gov/GTSS/rdPage.aspx?rdReport=OSH GTSS.ExploreByLocatio n\&is $\mid$ Country=ch\&is $\mid$ DataSource $=$ GATS\&is $\mid$ Location=1475\&is $\mid$ Topic $=$ T06\&is IWHORegio $\underline{\mathrm{n}=W P R \& i s \mid Y e a r=20102010 \& \mathrm{rdRnd}=93116}$

10. Creamer M, Wang T, Babb S, et al. Tobacco Product Use and Cessation Indicators Among Adults - United States, 2018. MMWR Morbidity and mortality weekly report. 2019 Nov 15;68:1013-9.

11. Santé Publique France. Santé Publique France [Internet]. Santé Publique France. Available from: https://www.santepubliquefrance.fr

12. Deszpot $T$. Le tabac, une barrière contre le Covid-19? Attention aux fausses infos [Internet]. LCI. 2020. Available from: https://www.lci.fr/sante/coronavirus-le-tabacprotege-du-covid-19-attention-aux-fausses-infos-sur-les-fumeurs-2150848.html

13. Centre d'épidémiologie et de santé publique des armées, Service de Santé des Armées, Ministère des Armées. Investigation de l'épidémie de COVID-19 au sein du Groupe Aéronaval 21 janvier-13 avril 2020. Ministère des Armées; 2020 May. Report No.: Document n`929/ARM/SSA/CESPA.

14. Chen Q, Zheng Z, Zhang C, Zhang X, Wu H, Wang J, et al. Clinical characteristics of 145 patients with corona virus disease 2019 (COVID-19) in Taizhou, Zhejiang, China. Infection. 2020 Apr 28;

15. Li J, Li S, Cai Y, Liu Q, Li X, Zeng Z, et al. Epidemiological and Clinical Characteristics of 17 Hospitalized Patients with 2019 Novel Coronavirus Infections Outside Wuhan, China. 2020.

16. Liu W, Tao Z-W, Lei W, Ming-Li Y, Kui L, Ling Z, et al. Analysis of factors associated with disease outcomes in hospitalized patients with 2019 novel coronavirus disease.

Chinese Medical Journal. 2020 Feb 1;133:1. 
Low rate of daily active tobacco smoking in patients with symptomatic COVID-19. Qeios. 2020 May 9;

18. Mo P, Xing Y, Xiao Y, Deng L, Zhao Q, Wang H, et al. Clinical characteristics of refractory COVID-19 pneumonia in Wuhan, China. Clinical infectious diseases : an official publication of the Infectious Diseases Society of America. 2020 Mar 16;

19. Shi Y, Yu X, Zhao H, Wang H, Zhao R, Sheng J. Host susceptibility to severe COVID-19 and establishment of a host risk score: findings of 487 cases outside Wuhan. Critical Care. 2020 Dec 1;24.

20. Wan S, Xiang Y, Fang W, Zheng Y, Li B, Hu Y, et al. Clinical Features and Treatment of COVID-19 Patients in Northeast Chongqing. Journal of Medical Virology. 2020 Mar 21;92.

21. Zhang J, Dong X, Cao Y-Y, Yuan Y, Yang Y, Yan Y, et al. Clinical characteristics of 140 patients infected by SARS-CoV-2 in Wuhan, China. Allergy. 2020 Feb 19;

22. Zhang X, Cai H, Hu J, Lian J, Gu J, Zhang S, et al. Epidemiological, clinical characteristics of cases of SARS-CoV-2 infection with abnormal imaging findings. International Journal of Infectious Diseases. 2020 Mar 1;94. 


\section{doi:10.20944/preprints202004.0445.v2}

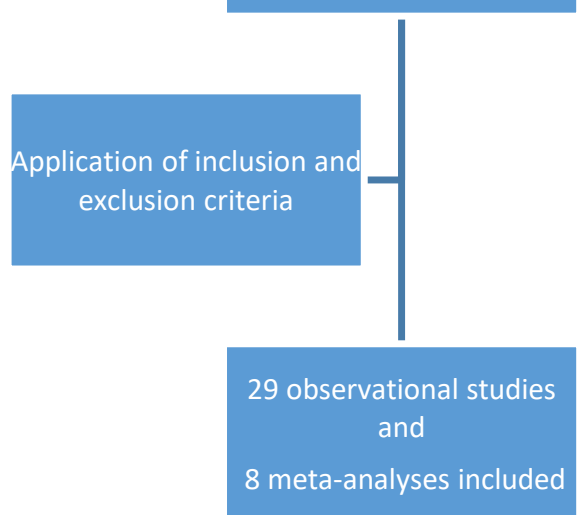

Non-inclusion of meta-

nalyses and studies with incomplete data 
Peer-reviewed version available at Clinical Pulmonary Medecine 2020, 27, 99-104; doi:10.1097/CPM.00000000000000364

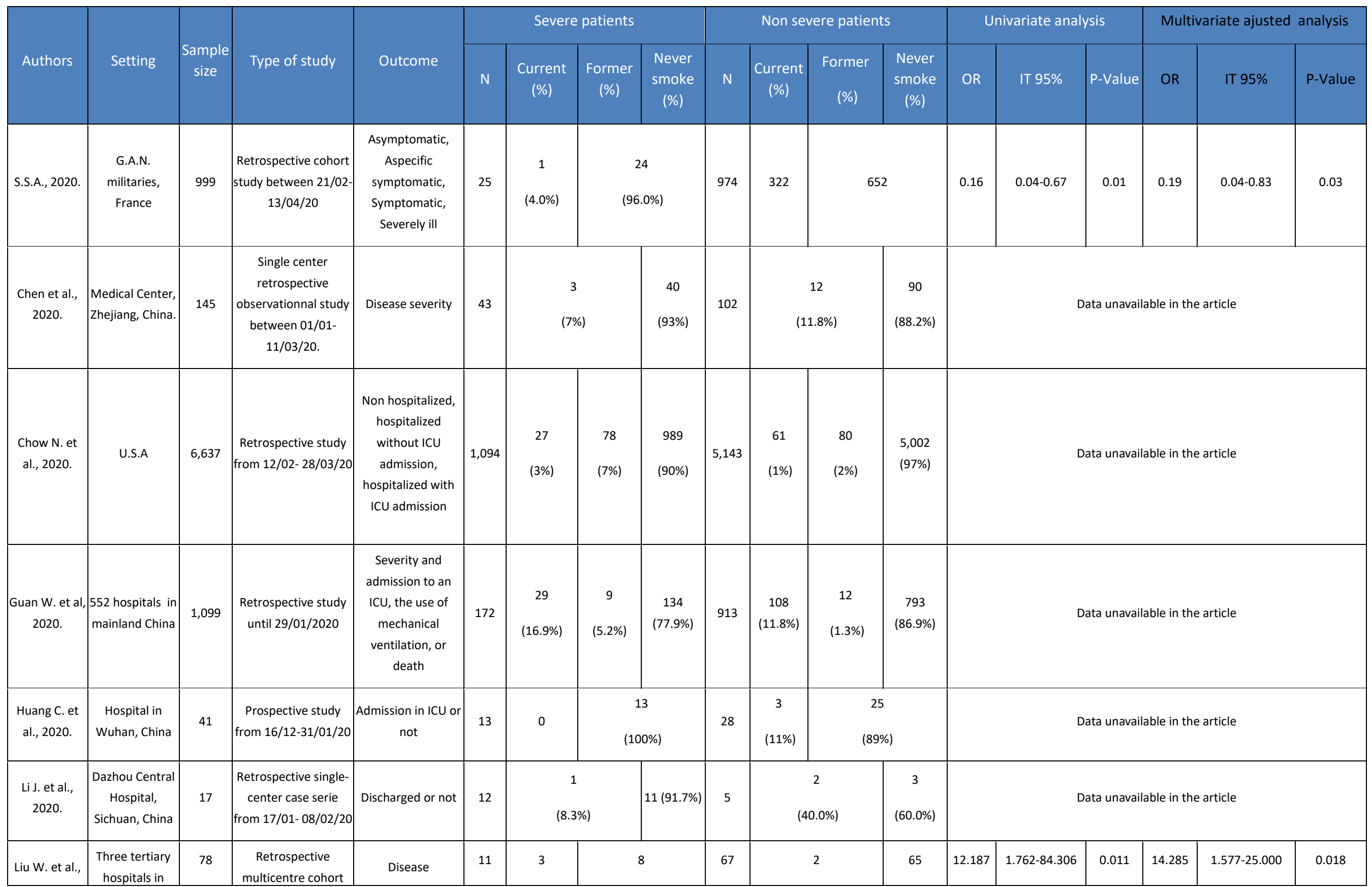




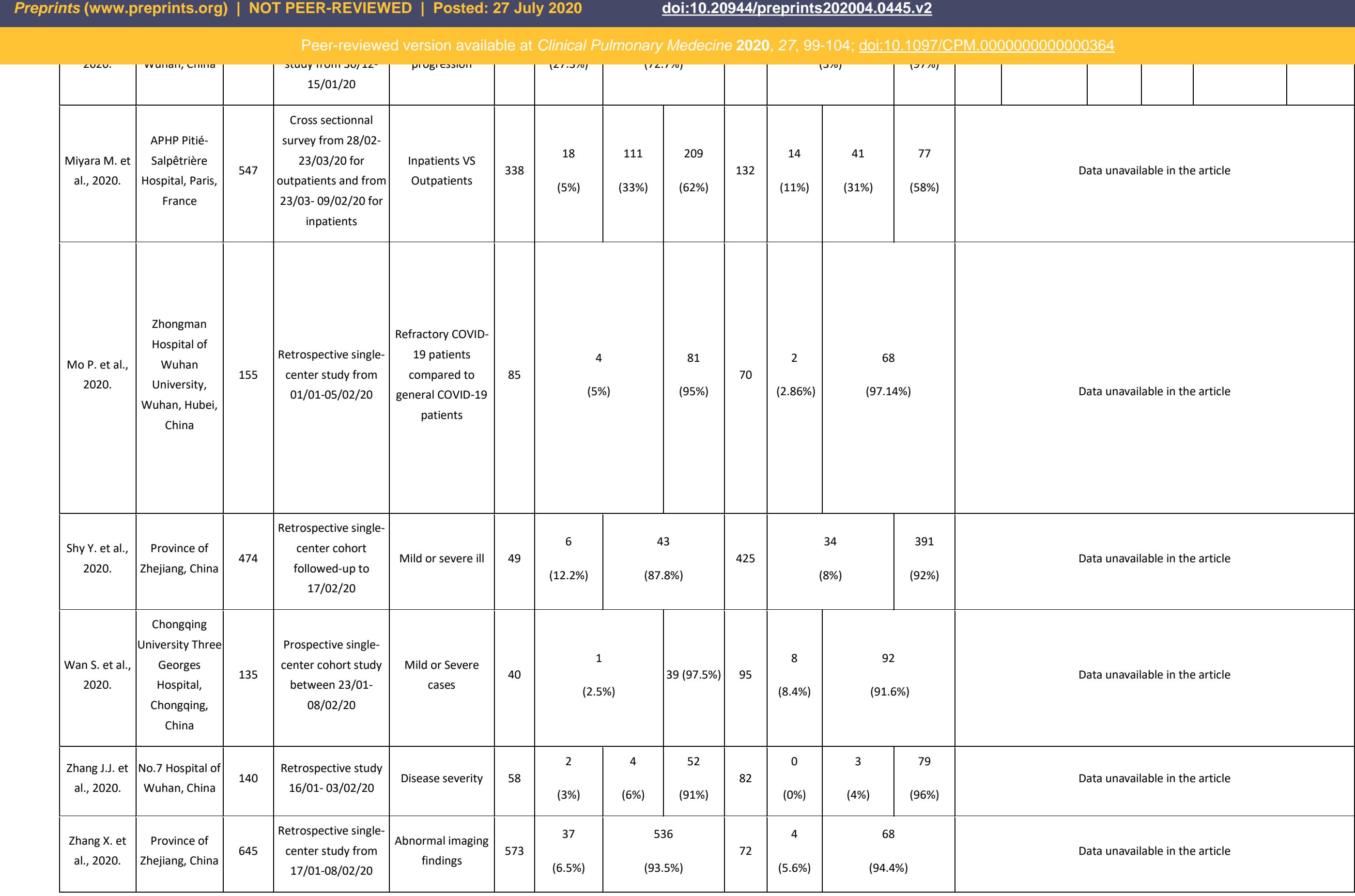




\begin{tabular}{|c|c|c|c|c|c|c|c|c|c|c|}
\hline \multirow{2}{*}{ Authors } & \multirow{2}{*}{ Country } & \multirow{2}{*}{ Outcome } & \multirow{2}{*}{ Odds-Ratio } & \multirow{2}{*}{$\begin{array}{c}95 \% \mathrm{TI} \\
\text { lower born }\end{array}$} & \multirow{2}{*}{$\begin{array}{c}95 \% \mathrm{TI} \\
\text { higher born }\end{array}$} & \multirow{2}{*}{ P-Value } & \multirow{2}{*}{$\begin{array}{l}\text { Sample } \\
\text { weight }\end{array}$} & \multicolumn{3}{|c|}{ Part of total outcome sample (\%) } \\
\hline & & & & & & & & Current smoker & Former smoker & Smoking history \\
\hline S.S.A. & France & Current smoker & 0.19 & 0.04 & 0.83 & & 999 & 9.866 & & \\
\hline Chen T. et al. & China & Smoking history & 0.563 & 0.150 & 2.103 & & 145 & & & 20.308 \\
\hline \multirow{2}{*}{ Chow N. et al. } & \multirow{2}{*}{ U.S.A } & Current smoker & 2.239 & 1.416 & 3.540 & & \multirow{2}{*}{6,637} & 65.544 & & \\
\hline & & Former smoker & 4.931 & 3.583 & 6.785 & & & & 79.657 & \\
\hline \multirow{2}{*}{ Guan W. et al. } & \multirow{2}{*}{ China } & Current smoker & 1.589 & 1.014 & 2.489 & & \multirow{2}{*}{1,085} & 10.715 & & \\
\hline & & Former smoker & 4.439 & 1.835 & 10.739 & & & & 13.022 & \\
\hline Li J. et al. & China & Smoking history & 0.136 & 0.009 & 2.062 & & 17 & & & 2.381 \\
\hline Liu W. et al. & China & Smoking history & 14.285 & 1.577 & 25.000 & & 78 & & & 10.924 \\
\hline \multirow{2}{*}{ Myiara M. et al. } & \multirow{2}{*}{ France } & Current smoker & 0.474 & 0.225 & 0.999 & & \multirow{2}{*}{470} & 4.641 & & \\
\hline & & Former smoker & 0.997 & 0.640 & 1.553 & & & & 5.641 & \\
\hline Mo P. et al. & China & Current smoker & 1.679 & 0.298 & 9.449 & & 155 & 1.530 & & \\
\hline Shy Y. et al. & China & Smoking history & 1.604 & 0.637 & 4.038 & & 474 & & & 66.387 \\
\hline Wan S. et al. & China & Current smoker & 0.294 & 0.036 & 2.430 & & 135 & 1.333 & & \\
\hline Zhang J.J. et al. & China & Former smoker & 2.026 & 0.435 & 16.750 & & 140 & & 1.680 & \\
\hline \multirow[t]{2}{*}{ Zhang X. et al. } & China & Current smoker & 1.173 & 0.406 & 3.393 & & 645 & 6.370 & & \\
\hline & & & & & & & TOTAL & 100 & 100 & 100 \\
\hline \multirow{3}{*}{ Global outcomes } & & Smoking history & 2.743 & 0.626 & 5.888 & 0.06112 & 714 & & & \\
\hline & & Current smoker & 1.783 & 1.082 & 3.109 & 0.1225 & 10,126 & & & \\
\hline & & Former smoker & 4.596 & 3.137 & 7.173 & 0.01869 & 8,332 & & & \\
\hline
\end{tabular}




\section{doi:10.20944/preprints202004.0445.v2}

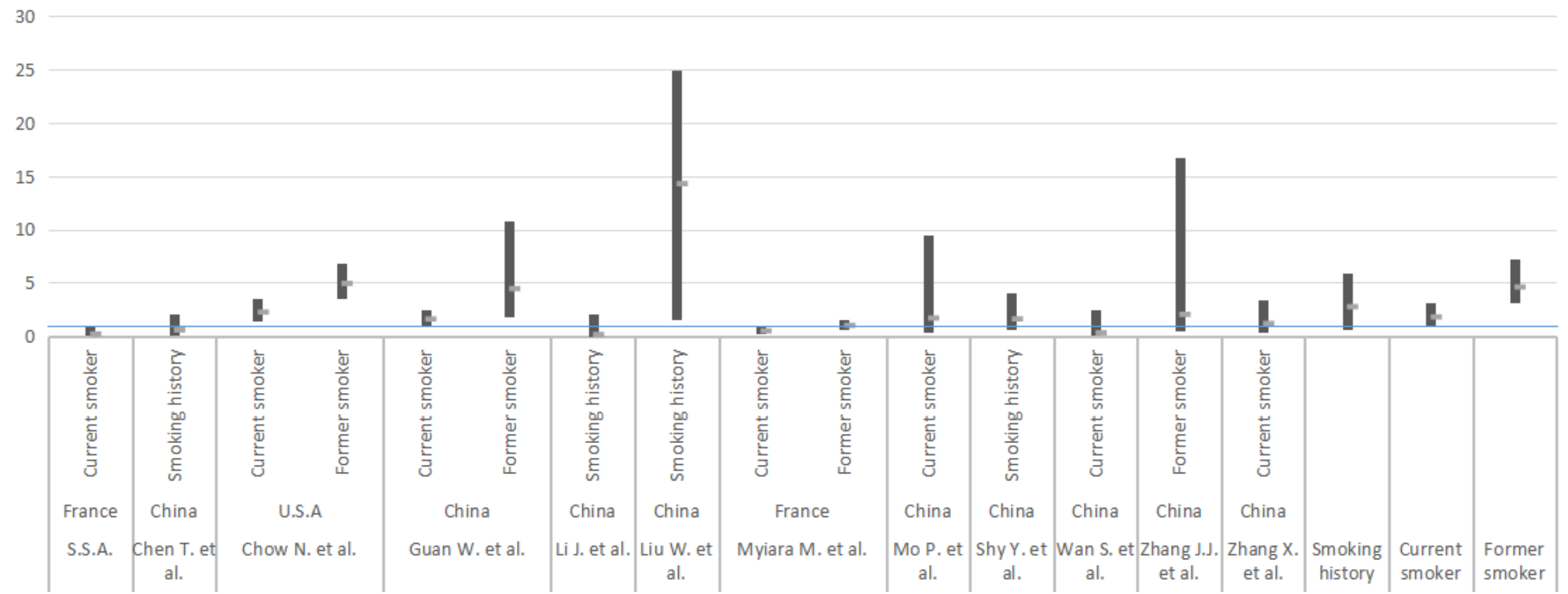

